\title{
A comunicação pública na mediação do debate sobre a política pública de educação numa esfera pública local ${ }^{1}$
}

\author{
Regina Célia ESCUDERO CÉSAR ${ }^{2}$
}

\section{Resumo}

Refletimos sobre a ação comunicativa que articula os movimentos sociais da sociedade civil na esfera pública, em especial na discussão sobre a educação pública numa esfera local. Utilizamonos da interpretação hermenêutica em profundidade nas fases da pesquisa. Defendemos a comunicação pública como mediadora da relação Sociedade Civil-Estado numa esfera pública inclusiva, democrática e pautada na interação entre sujeitos igualmente competentes e ativos do processo.

Palavras-chave: público, esfera pública, sociedade civil, comunicação, educação.

\begin{abstract}
We reflected on the communicative action which articulates the social movements of the civil society in the public sphere, especially in the discussion about public education. We have used the hermeneutic interpretation in depth both researches. We defended public communication as a mediator of the relationship Civil Society-State in the public sphere, under an inclusive and democratic perspective based on interactions among equally competent and active subjects in this process.
\end{abstract}

Keywords: public; public sphere; civil society; communication; education.

Neste artigo apresentaremos os resultados de uma pesquisa de doutorado por nós desenvolvida $^{3}$, na qual pesquisamos o conceito de comunicação pública, além de situálo como mediador e mobilizador do debate sobre a política pública de educação numa comunidade específica da cidade de Londrina-PR. No desenrolar da narrativa muitas vezes serão apresentadas as avaliações dos sujeitos da pesquisa sobre a temática em

1 Trabalho apresentado à quarta edição da Revista Ação Midiática - Estudos em Comunicação, Sociedade e Cultura, publicação ligada ao Programa de Pós-Graduação em Comunicação e Sociedade, da Universidade Federal do Paraná.

2 Professora do Departamento de Comunicação Social da Universidade Estadual de Londrina. Doutora em Comunicação Social pela USP. E-mail: escudero@uel.br

3 A comunicação pública como práxis no processo de mediação e mobilização da sociedade civil na esfera pública. 2012. Tese (doutorado) - Universidade de São Paulo, 2012. Financiada pela Capes. 


\section{REVISTA AÇÃOMIDIÁTICA - Estudos em Comunicação, Sociedade e Cultura}

Universidade Federal do Paraná

Programa de Pós Graduação em Comunicação

Vol 2. No 2. Ano 2012

análise; entretanto, como forma de resguardar suas identidades, os nomes apresentados serão todos fictícios.

É importante salientar que a comunidade tem uma raiz singular: foi a primeira ocupação urbana desta cidade e por isso é bastante estigmatizada pela população em geral, sendo considerada local violento e perigoso. Muitas vezes, seus integrantes têm dificuldade em arrumar emprego quando mencionam o seu local de residência. Trata-se de uma comunidade cuja maioria dos moradores vive em situação socioeconômica precária e muitas vezes dependente dos programas sociais do Estado.

Entretanto, é também marcada por uma história de mobilização que envolveu toda a sua "construção". Inicialmente, em 1985, eram 60 pessoas que se instalaram no local, e hoje, segundo dados do IBGE/2010, são 10.086 habitantes. Suas primeiras casas foram construídas em sistema de mutirão e, em 1990, iniciou-se a construção de uma creche, um posto de saúde e uma escola. Em 1989, foi organizada a primeira associação de moradores da comunidade. Em fevereiro de 1995, formou-se o Conselho de entidades, que tinha como objetivo fortalecer as reivindicações da comunidade junto aos órgãos competentes. Em função da mobilização da comunidade por meio deste Conselho, muitas conquistas foram obtidas, tais como: pavimentação das ruas, transporte coletivo, construção de escolas, postos de saúde, entre outras melhorias. A forma de organização dos moradores neste Conselho era diferenciada tanto no sentido da participação quanto na sua condução, que era essencialmente democrática.

As fases da pesquisa bibliográfica e empírica da tese que embasa este artigo fundamentaram-se na metodologia da interpretação hermenêutica em profundidade (Thompson, 1995) que consiste num método de compreensão das formas simbólicas que perfazem o mundo social, as quais "são construções significativas que exigem uma interpretação; elas são ações, falas, textos que, por serem construções significativas, podem ser compreendidas.” (THOMPSON, 1995, p. 357).

Para a metodologia da interpretação hermenêutica, as produções simbólicas que expressam a natureza do mundo sócio-histórico não podem ser consideradas um campo-objeto que pode ser observado objetivamente, mas constituem um camposujeito, pois são elaboradas a partir de um processo contínuo de reflexão do sujeito sobre a realidade construída por ele mesmo, ao buscar compreender a si próprio por meio dela. Thompson (1995) considera que tanto os analistas como os sujeitos envolvidos na análise hermenêutica - campo-sujeito-objeto - agem motivados pela 
reflexão e avaliação da realidade circundante. Os resultados dessa análise hermenêutica podem ser apropriados pelos sujeitos e influenciar na transformação da realidade sóciohistórica, embora este não seja o objetivo e nem o critério de validação deste método investigativo. Para Thompson:

O mundo sócio-histórico não é apenas um campo-objeto que está ali para ser observado; ele é também um campo-sujeito que é construído, em parte, por sujeitos que, no curso rotineiro de suas vidas quotidianas, estão constantemente preocupados em compreender a si mesmos e aos outros, e em interpretar as ações, falas e acontecimentos que se dão ao seu redor (THOMPSON, 1995, p. 358).

Assim, a fase empírica desta pesquisa teve como objetivo alavancar o debate entre os moradores da comunidade sobre a temática da educação, definida por eles como prioritária, especialmente devido a um episódio ocorrido em março de 2011 envolvendo uma de suas escolas públicas e divulgado num dos jornais locais. A forma como tal acontecimento foi apresentado pela mídia e também pela diretora da comunidade concorreu para fortalecer ainda mais o estigma negativo desta comunidade junto à população londrinense. Por meio da metodologia hermenêutica em profundidade, foi possível avaliar a percepção dos sujeitos diretamente envolvidos sobre a questão em debate, trazendo à tona suas opiniões dentro de uma esfera pública na qual todos participaram de forma igualitária. Tal pesquisa foi realizada num primeiro momento através de entrevistas individuais em profundidade; num segundo momento todos os sujeitos foram convidados a conhecer os resultados da pesquisa e debatê-los coletivamente, dentro de uma esfera pública conduzida pelos princípios da comunicação pública; e numa terceira e última etapa, tais resultados foram apresentados aos educadores responsáveis pela condução da política pública de educação na cidade. Em todas as etapas da pesquisa foram levantadas críticas, avaliações e alternativas para a solução da problemática da educação na comunidade.

Ressaltamos que, tanto no momento da seleção dos sujeitos de pesquisa quanto na determinação de seus papéis no contexto sócio-histórico e na escolha das estratégias de coleta de dados, levamos em consideração a possibilidade de ampliar e aprofundar as discussões sobre a temática da educação no espaço público. Deste modo, a pesquisa buscou, ao mesmo tempo, levantar os dados e provocar um debate entre os sujeitos a respeito da problemática pública em questão, na perspectiva de atuar coletivamente na 
transformação da realidade. Neste artigo apresentamos um recorte dos resultados dessa pesquisa, cuja íntegra pode ser consultada no site da biblioteca da Escola de Comunicação e Artes da Universidade de São Paulo, no endereço: http://www.teses.usp.br/teses/disponiveis/27/27154/tde-04032013-152158/pt-br.php.

$\mathrm{O}$ fato ocorrido na escola e divulgado pela mídia deu-se quando algumas pessoas quebraram vidros da escola no período noturno das aulas. Após este incidente, a diretora do colégio (recém-empossada) chamou a polícia para resolver a situação, o que gerou importantes constrangimentos entre os membros da comunidade, além de uma repercussão negativa na cidade, uma vez que a imprensa local ao divulgar o fato enfatizou o ato de vandalismo isoladamente, sem uma análise do seu contexto. Por meio das entrevistas que realizamos, o posicionamento da diretora foi avaliado como um ato de total intolerância, insensibilidade e distanciamento dos problemas do bairro. Segundo grande parte dos entrevistados, a atitude da diretora afastou, ainda mais, a comunidade da escola e reafirmou, junto à sociedade londrinense, o estereótipo negativo do bairro. Em sua opinião outras atitudes poderiam ter sido tomadas antes de se optar pelo ato extremo de chamar a polícia. Além disso, consideraram que a abordagem dada pela mídia ao problema foi superficial e sensacionalista.

\section{1) Atores e interlocutores da esfera pública}

Segundo Costa (1997), as mídias e os interesses econômicos e políticos são os atores da esfera pública; e o público, sua plateia sem voz pública efetiva. Importante fenômeno surge quando parte dessa 'plateia' se organiza para reivindicar aos atores da esfera pública um tratamento adequado das questões de interesse público. Assim, por meio de movimentos sociais, o grupo transformado em plateia atua de modo a resgatar seu papel como público. O autor afirma ainda que a esfera pública não é somente influenciada pelos meios de comunicação, mas também pelos espaços de comunicação interpessoal e pelas redes colaborativas e informais de intercâmbio. Conforme esta concepção, estes elementos relativizam a ação manipuladora das mídias e apontam para a possibilidade de formas discursivas de comunicação dentro da esfera pública.

Graças a sua capacidade crítica e analítica, este público submete as mensagens dos atores da esfera pública a uma avaliação em termos qualitativos, tanto em relação ao seu conteúdo plástico quanto persuasivo, pois seu contexto sociocultural e suas redes 
interpessoais de comunicação permitem uma apreciação mais criteriosa das mesmas.

Quando essas redes informais de comunicação interpessoal organizam-se em uma estrutura mais complexa, passam a atuar como movimentos sociais ou associações civis e assumem, assim, maior visibilidade no contexto da esfera pública. A seguir apresentamos algumas avaliações dos sujeitos desta esfera pública a respeito da problemática em análise:

A diretora não deveria ter exposto tanto os alunos, pois apesar de tudo existem muitos alunos bons na escola. Se fosse ela mostraria mais as dificuldades que eles enfrentam, faria mais reivindicações, pediria suporte do Núcleo, melhorias em geral (Isis-professora).

Acredito que delatar para o jornal sobre o assunto não é a melhor maneira de lidar com o problema, pois pode provocar mais raiva em quem ameaça a diretora. O que deveria fazer era entrar em contato com a patrulha escolar. As ameaças vêm de fora, não são de alunos (Raquel-estudante).

Neste caso específico, constatamos, em um primeiro plano, que esta esfera pública local é formada por um público preocupado com as ações que envolvem a comunidade, pois ele percebeu o posicionamento negativo da diretora e a repercussão do fato na imprensa. De forma mais substancial, percebemos que, pela falta de integração da política de educação com as redes intersetoriais de políticas públicas da região, a diretora agiu de modo isolado, por não ter uma visão global da realidade em que estava envolvida. Existe na comunidade um projeto inovador, que é a organização das políticas públicas atuantes na região em uma rede intersetorial, que se reúne mensalmente a fim de discutir e agir sobre os problemas locais de forma integrada, possibilitando assim uma visão global das questões que envolvem a população. Mas a grande maioria dos representantes da política pública da educação não tem participado destas reuniões, o que lhes tira a possibilidade de um melhor relacionamento e conhecimento da comunidade.

A diretora desta escola não se abre e nem participa das redes intersetoriais, sou a única representante de escolas desta região que participo das redes. As escolas se encastelam. (Bia- diretora)

Esta Escola não conhece a comunidade. A política de educação praticada na comunidade é da pior qualidade (Vado- morador).

Hoje deveria haver um caminho de discussão. O Conselho de Educação que tem representantes governamentais $e$ não governamentais, não tem discussões com os verdadeiros atores. Já foi 
colocada esta situação aos representantes do Núcleo de Educação. $O$ sistema de educação é impositivo, não tem uma discussão com a base (Rui-assistente social).

Por estes posicionamentos pode-se perceber que os atores desta comunidade têm uma avaliação crítica sobre a questão, independentemente do papel social ou cultural que assumem no debate. Conforme a análise de Costa (1997) apresentada anteriormente, o contexto das relações sociais transforma a plateia em um público ativo, que interfere criticamente sobre a sua realidade, o que pode ser observado nesta pesquisa de doutorado, conforme os relatos apresentados. Entre as ações deflagradas por este público estão reuniões informais entre pais, alunos e professores organizadas por alguns dos moradores da comunidade, a fim de definir novos encaminhamentos para a situação que possibilitem a continuidade das atividades da escola na comunidade. Percebe-se assim a existência de um público comprometido e participante do debate sobre as questões públicas que o envolve. Vale salientar que a articulação destas reuniões partiu da iniciativa de membros da comunidade que não tinham vínculo direto ou indireto com a escola, mas mesmo assim a consideravam um patrimônio público da comunidade que deve ser respeitado por todos. Os veículos de comunicação utilizados para a divulgação das reuniões foi o boca-a-boca e telefonemas, meios ao alcance das características socioculturais do público envolvido no episódio, cumprindo assim algumas das propriedades da comunicação pública, que é ser acessível e não-restritiva.

\section{2) O público do século XXI}

A concepção que defendemos a respeito do comportamento coletivo, conhecido como público tem uma dimensão ético-política e sócio-histórica, pois o consideramos um sujeito público, cuja natureza social é coletiva e transformadora, mas, fundamentalmente, delimitada por um contexto sócio-histórico. Este ente público é formado por pessoas, indivíduos, que se relacionam entre si e com a realidade externa, de forma processual, norteados por uma determinada ideologia. As forças política e de transformação desse ente público fundamentam-se em sua natureza ético-política, que é definida pelo contexto social, o qual pode ser modificado a partir de uma visão crítica do mesmo, com base em um novo padrão ético-moral.

O público formado na esfera pública organiza-se, processual e dialeticamente, com base em conceitos ético-políticos e interage com a sociedade, sendo seu sujeito- 
objeto de transformação. Neste sentido, creditamos à comunicação pública a possibilidade de inclusão democrática de indivíduos oriundos de diferentes classes sociais e extratos políticos e culturais nesta nova esfera pública que vem sendo criada por este ente público. Este público faz parte do contexto da esfera pública, age sobre este como seu mobilizador (sujeito coletivo) e, ao mesmo tempo, é objeto deste contexto. Seu protagonismo está vinculado a um ideário transformador, isto é, a uma vontade política de interferir sobre e neste contexto. Diferentes forças concorrem no cenário da esfera pública e estas nem sempre favorecem ações organizadas e racionais. Apesar destes contextos desfavoráveis (ou nem sempre favoráveis), este grupo continua a ser um público, formador de opinião e da sociedade civil, por meio da comunicação pública.

$\mathrm{Na}$ perspectiva da teoria funcionalista da comunicação, este público nem sempre está pronto para atuar na esfera pública, pois não contempla todos os seus requisitos, ou seja, um nível de informação, de crítica, de racionalidade e organização que o torne "apto" a participar dela. Entretanto há, neste sujeito coletivo, uma disposição política para agir sobre seu contexto, disposição esta que é também transformadora, pois é gerada pela mobilização em torno de interesses públicos. Assim, o conceito de público que defendemos situa-se numa visão dialética que se inscreve numa realidade sócio-histórica específica e, neste sentido, é um sujeito coletivo transformador de seu contexto e ao mesmo tempo transformado por ele. Este processo é, fundamentalmente, educativo, pois se constrói numa relação dialética entre o sujeito público e o contexto cultural e sócio-histórico que o envolve e caracteriza.

Este novo público tem percebido a necessidade de se posicionar nas diferentes instâncias deliberativas, tais como associações de moradores e comitês, com representações locais e até globalizadas. Não importa a dimensão, este agrupamento coletivo tem se inserido no processo de deliberação pública. Vale salientar, porém, que o caráter normativo do público deve sempre ser percebido nesta dimensão sóciohistórica e ético-política, para a garantia da participação cidadã na esfera pública brasileira. Nesse sentido, Gomes e Maia ressaltam que:

Os públicos do século XXI têm se mostrado suficientemente convencidos da importância dos debates civis e suficientemente astutos ao lidar com a comunicação de massa para usar em benefício da discussão pública política e da conversação civil os indispensáveis recursos de que tal comunicação dispõe. Além disso, e de forma ainda mais relevante, contrariamente ao que 
se pensava no início dos anos 60, a comunicação de massa não pode nem deve ser pensada como adversária automática de uma discussão e de uma visibilidade pública favoráveis à democracia. Ao contrário, o que hoje é evidente é que a comunicação de massa leva à prática política - tanto aquela do sistema político quanto aquela dos cidadãos - ao máximo histórico de discutibilidade e de visibilidade (GOMES; MAIA, 2008, p. 66).

Acreditamos que, de fato, há uma mudança de sentido na relação massa e público no âmbito dos movimentos coletivos da atualidade. Livingstone (2005) afirma que existe uma retroalimentação entre estes dois agrupamentos coletivos na formação da opinião pública, o que vincula sua natureza social a uma concepção dialética e sóciohistórica da realidade, proporcionando um posicionamento diferenciado destes agrupamentos coletivos frente às questões de interesse público. A separação entre o público racional e a massa acrítica e amorfa, própria dos conceitos funcionais, cede lugar ao aparecimento de uma nova visão, dialética e mais comprometida com as características que movem a comunicação na dinâmica histórica da sociedade multicultural da atualidade. Desse ponto de vista, nem a massa é tão acrítica e distante da realidade, nem o público é movido somente pela razão e a opinião pública é o resultado deste processo de entrelaçamento entre os sujeitos que atuam na esfera pública.

\section{3) A comunicação pública no processo de mediação e mobilização da esfera pública}

A comunicação, neste processo, atua na alavancagem das relações interativas da sociedade contemporânea. Essencialmente, este novo público é um receptor ativo que participa das relações de comunicação e não mais o receptor passivo frente às mensagens do emissor conforme apregoado pela teoria funcional da comunicação. A relação comunicativa organiza-se por uma visão circular, que se constrói no processo de interação entre os envolvidos. Pautamo-nos, neste sentido, pelo processo de mediação cultural e de comunicação de Martin-Barbero (2003).

A contribuição de Martin-Barbero (2003) para os estudos da teoria da comunicação foi o deslocamento do fenômeno da cultura de massa de uma compreensão positivista, essencialmente tecnológica e de degradação cultural, para uma visão histórica do fenômeno, que deixa de ser impositiva para ser consensual. Ele propõe que a análise do processo cultural se desloque dos meios para as mediações, situando o 
debate atual sobre a transnacionalização da comunicação no contexto da América Latina que, em sua opinião, necessita de uma reconfiguração política, uma vez que, para esse autor, o receptor deve ser o ator político deste novo cenário, que é o espaço de transformação social e de revalorização das articulações e mediações da sociedade civil. Essa visão muda a concepção de "sujeitos políticos" que, nesse caso, passam a ser todos os diferentes atores sociais que formam uma nação.

A convergência dos processos transnacionais a esta nova concepção do político faz emergir, entre as várias nações, uma profunda valorização do cultural, que assinala dimensões inéditas do conflito social e da formação de novos sujeitos regionais, religiosos e sexuais, assim como de novas formas de rebeldia e resistência. Deixa-se o plano seguro das tecnologias, próprio da visão instrumentalista da comunicação, e passa-se a considerar os conflitos e os processos criativos que afloram nas relações sociais a partir das identidades culturais dos sujeitos nelas envolvidos.

Os princípios da comunicação pública, cuja natureza é democrática, nãorestritiva, não-especializada e não-excludente, vão ao encontro desta necessidade de reconfiguração da esfera pública mediada pela comunicação, uma vez que tem como perspectiva a abertura de canais democráticos que viabilizem o livre fluxo de informações entre os seus atores. Seus veículos são adequados às características culturais de cada realidade, às vezes informais e simples; outras, mais sofisticados, que requerem suporte tecnológico. Diante destas possibilidades, a comunicação pública torna-se acessível a todos, sem restrições. Seu objetivo é a discussão de temas de interesse comum na esfera pública e o seu resultado é a formação da opinião pública e o fortalecimento da cidadania. Segundo Gomes e Maia:

\footnotetext{
Neste esquema, a esfera pública é basicamente um meio para a produção de opinião pública e o modo fundamental de existência da esfera pública é a comunicação pública, que se materializa em um conjunto de estruturas para uma comunicação generalizada (quer dizer, não restritiva, não-especializada, não-excludente). A matéria básica da comunicação pública (em outras palavras, aquilo que responde à pergunta: qual é o objeto da comunicação generalizada?) são questões, idéias, formulações, problematizações, sugestões provenientes das interações vitais da vida em sociedade. (GOMES; MAIA, 2008, p. 85)
}

A comunicação pública atribui status ético-moral ao espaço público fundado na livre discussão e na igualdade de participação, pois é desse modo que seus participantes 
divulgam suas ideias, tornando-as públicas e aperfeiçoando-as em meio à crítica e à autocrítica, como afirma Esteves:

\begin{abstract}
A sua articulação é estabelecida pelos princípios da liberdade e igualdade, os quais marcam também o forte cunho político-ético-moral e emancipatório da comunicação pública. O significado social dos critérios referidos pode ser assim expresso: livre participação de todos os interessados (possibilidade de um alargamento ilimitado do público), livre discussão de temas e assuntos (laicização da política e da cultura em geral) e igualdade de estatuto de todos os participantes (competência reconhecida em função, e só em função, da validade dos argumentos reconhecidos) (ESTEVES, 2003, p. 36).
\end{abstract}

O conceito de comunicação pública que defendemos neste artigo está vinculado à sua característica de articulação dos interesses públicos na esfera pública, que é o lócus do debate, das argumentações, do plural, do encontro de ideias contraditórias, assim como o lugar de visibilidade da opinião pública que é nele gerada, como resultado das discussões desenvolvidas. Para esta esfera são encaminhados os problemas da sociedade civil (associações, organizações, movimentos sociais) que emergem das relações estabelecidas na esfera pública em busca de um entendimento.

Consideramos importante compreender a comunicação pública como um resgate da função social do comunicador na esfera pública democrática, não como uma especialidade da comunicação, mas como um conceito em permanente construção, a partir da dinâmica sociocultural. Refere-se a uma postura crítica e transformadora do comunicador social diante das necessidades e demandas sociais que se apresentam na atualidade. Trata-se de um processo que requer compromisso metodológico do comunicador com as transformações da realidade, que devem se concretizar por meio de um posicionamento político e engajado desse profissional na construção democrática de seu entorno. Ao assumir esta postura política e transformadora, o profissional trabalha na mediação entre os interesses públicos situados na esfera pública e as diferentes forças que concorrem dentro dela. Ações deste tipo exigem um compromisso político que nunca pode ser neutro, ou seja, ou se atende os interesses particulares ou os interesses públicos, pois não é possível servir a estes dois senhores ao mesmo tempo.

Apesar de a expressão comunicação pública possuir forte vínculo com o Estado, ela envolve, fundamentalmente, o relacionamento entre o cidadão e o Estado. Entretanto, chamamos a atenção para o ideário central que vem sendo ocupado pela comunicação pública na América Latina, que, na avaliação de Brandão (2009), tem 
retomado o verdadeiro sentido da comunicação:

\begin{abstract}
A restauração da democracia e o consequente crescimento de novas formas de vivências democráticas despertaram a necessidade de informação voltada para a construção da cidadania. A própria noção de cidadania sofre mudança e começa a ser entendida de forma menos passiva e mais participativa, apreendida como o livre exercício de direitos e deveres, situação para a qual só se está preparado quando existem condições de informação e comunicação. A comunicação é hoje um ator político proeminente e é parte constituinte da formação do novo espaço público (BRANDÃO, 2009, p.10).
\end{abstract}

Portanto, inserimo-nos na intenção coletiva de construção deste paradigma da comunicação pública comprometido com o interesse público manifesto na esfera pública, a partir da ação da sociedade civil e dos profissionais de comunicação envolvidos com o fortalecimento da democracia brasileira.

\title{
4) A comunicação pública e a construção da democracia no Brasil
}

A democracia somente se efetiva por meio da participação do povo nas deliberações de interesse público, mas, para que isto ocorra, é fundamental que haja liberdade de expressão e canais de comunicação que possibilitem essa participação. Garantidas essas condições basilares à constituição de uma esfera pública democrática, é possível a formação de uma opinião pública autônoma, que se organiza enquanto sujeito coletivo mobilizador desta. A comunicação pública é, essencialmente, o meio que viabiliza a discussão e a deliberação dos assuntos de interesse público, de forma democrática.

A comunicação possibilita a visibilidade da identidade dos diferentes grupos e de sua inclusão na nova esfera pública, cujo debate se dá entre forças conflitivas e diversas e é fundamental para o amadurecimento da democracia. Por meio do acesso à informação sobre a realidade em que vive, o indivíduo torna-se sujeito capaz de transformar sua história, o que é possível somente quando ele discute e se organiza em grupos que questionam e interferem no processo social ao defender o interesse público e coletivo. Este nó coletivo fortalece a esfera pública, pela defesa dos interesses públicos e da cidadania, num processo contínuo, fecundo e consciente a respeito de conquistas coletivas. 
A comunicação pública apresenta-se como a mídia capaz de promover tal inserção da comunidade nesta esfera pública de debate, por meio de uma linguagem acessível ao cidadão, que é seu sujeito coletivo. As sociedades democráticas modernas têm como princípio norteador a proteção do homem em sua dignidade. Este parâmetro é uma herança das sociedades democráticas do século XX, com base na Declaração dos Direitos Humanos (1948). Conforme Toro e Werneck (2007), esta Declaração sintetiza, num só documento, a preocupação de vários países em preservar a dignidade humana como um bem superior até mesmo em relação a questões econômicas, étnicas e culturais. Assim, o pressuposto básico da cidadania é o reconhecimento deste direito que, no Brasil, ainda é inacessível a muitos, conforme os autores:

\footnotetext{
No Brasil, ao incorporarmos aos direitos garantidos na nossa Constituição a íntegra da Declaração Universal dos Direitos Humanos (Título II- Dos Direitos Fundamentais, artigo $5^{\circ}$ ) e declararmos a dignidade humana como um dos fundamentos de nossa ação e de nosso modelo de democracia, nos comprometemos com a formulação de um projeto de desenvolvimento que não seja exclusivamente econômico, mas que seja baseado nos Direitos Humanos e que contribua para transformá-los de projeto ético em projeto público, em uma visão de mundo, um discurso, uma decisão e uma ação (TORO; WERNECK, 2007, p. 22).
}

Segundo Toro e Werneck (2007) é fundamental compreender que a democracia não se institui por decreto, de cima para baixo, mas é fruto de uma construção do cidadão que participa das discussões que são próprias da sociedade, em busca de um entendimento sendo, portanto, um processo de aprendizado. Numa sociedade democrática, os conflitos e suas negociações fazem parte de sua natureza, pois é a forma como os cidadãos se posicionam frente a eles que lhes dá um sentido democrático. As decisões não são outorgadas, mas frutos de discussões do cidadão na esfera pública, como se percebe na situação analisada na fase empírica de nossa pesquisa, na qual a sociedade civil local posicionou-se contrariamente à atitude tomada pela diretora da escola pública.

Vale salientar que no decorrer da pesquisa foram coletados outros depoimentos de representantes de escolas e, especialmente, entre aqueles ligados a cargos de direção que se manifestaram contrários à atitude da diretora, ficou evidente o profundo distanciamento entre eles e as características culturais da realidade em que estão inseridos. 
Um exemplo dessa realidade é a forma como uma das propostas da política pública de educação tem sido desenvolvida nesta escola. É recomendado aos alunos com dificuldades de aprendizagem que parem de estudar e só retornem quando atingirem idade compatível para frequentar as aulas o que constitui uma atitude excludente que os representantes do Estado tentam justificar afirmando que a política de educação prevê, neste caso, a sugestão ao aluno para que espere atingir a idade correta para participar do EJA: [...] são alunos problemáticos ou mais velhos que podem prejudicar o encaminhamento da sala de aula, justificou a profissional.

Transcrevemos a seguir um dos depoimentos que chamou muito a atenção, principalmente pelo fato de partir de uma jovem professora que se declarou surpresa com a realidade apresentada nas escolas da periferia:

[...] o professor é pego de surpresa quando se depara com a realidade deste aluno; a gente não está preparado para trabalhar com este público; a universidade não prepara a gente para atuar nestas comunidades.

Por este depoimento percebe-se o distanciamento entre os representantes do Estado e sua realidade. O Brasil tem ainda hoje uma jovem democracia representada por uma também jovem cidadania que é desigual em sua estrutura pois existe num contexto de privações sociais, econômicas, culturais, sem falar da falta de acesso a condições triviais de lazer que concorrem para a abstração de sua historicidade.

Telles (1994) aponta para o surgimento, no Brasil, de uma nova sociedade civil configurada pelo debate e pela negociação do bem público, porém situada num contexto definido como apartheid social, ou seja, onde as diferenças sociais são imensas mas continuam a ser tratadas como naturais por seus membros. É inquestionável a existência de avanços significativos na sociedade civil brasileira no que diz respeito a questões de interesse público, como a que se viu, por exemplo, nas intensas manifestações e mobilizações sociais que repercutiram no impeachment do Presidente da República, Fernando Collor, em 1992, assim como, em outras situações que envolvem os Novos Movimentos Sociais (NMSs), voltados a reivindicações em torno de temas ambientais, culturais, educacionais e étnicos. Entretanto, ainda há, neste contexto, uma relação equivocada entre os interesses públicos e privados embutidos nas entrelinhas desses 
movimentos sociais, os quais, muitas vezes, acabam por esfacelá-los, ao destituir a autonomia e a legitimidade da luta por tais anseios.

$\mathrm{O}$ acesso ao direito de participação e deliberação em temas de interesse público é um indicador concreto de cidadania e democracia. Não se cria um cidadão, pois este já é ente próprio das sociedades democráticas ocidentais, que se emancipa por meio de sua participação política. O direito ao exercício da cidadania é a base que sustenta e dá sentido à democracia. As propostas de comunicação pública que defendemos, inserem-se na defesa deste direito junto a segmentos da sociedade civil que não têm acesso ao exercício de sua cidadania nas esferas públicas do regime, dito democrático, existente no país.

A sociedade civil emergente tem no espaço público um local manifestar a diversidade de opiniões e argumentos dos públicos que dela participam. Assim, este é, verdadeiramente, um espaço democrático, no qual o ente público prevalece na defesa do bem público.

\section{Conclusão}

Compreendemos que a comunicação pública é, fundamentalmente, a base que mobiliza a esfera pública democrática, pois é aberta, democrática, não-restritiva, ou seja, todos têm iguais oportunidades de participação, todos, irrestritamente, são incluídos na discussão que envolve os interesses públicos.

A comunicação, quanto mais horizontal, mais inclusiva dos públicos em seu processo. Acreditamos que o público enquanto sujeito coletivo adquire dimensão éticopolítica e sócio-histórica ao assumir o papel de sujeito público, cuja natureza social é coletiva e transformadora, mas fundamentalmente delimitada por um contexto sóciohistórico. Entendemos que esse contexto é sempre movediço e, portanto, passível de ruptura pela força dos movimentos e das redes sociais, que, no processo contraditório das relações sociais, vão concretizando diferentes ideias e ações.

A sociedade civil, na atualidade, é formada por grupos com disposição política para tomar parte da esfera pública e a transformar. Ou seja, apesar de nem sempre se apresentar apto, segundo o modelo funcionalista de público, este sujeito coletivo tem disposição política para agir sobre seu contexto, transformando-o, impulsionado pela mobilização em torno de interesses públicos. Foi esse público, cuja vitalidade se dá pela 
sua disposição e comprometimento político e inserção num espaço público de debate, que conhecemos na realidade pesquisada.

Pela utilização da metodologia da interpretação hermenêutica em profundidade, percebemos que quando o profissional orienta suas atividades por este novo paradigma ético profissional, é possível adentrar em um fecundo processo de comunicação pública, que tem como horizonte as demandas democráticas da sociedade civil, a inclusão e a igualdade de oportunidade de expressão pública.

\section{REFERÊNCIAS}

BRANDÃO, Elisabeth Pazito. Conceito de comunicação pública. In: DUARTE, Jorge (Org.). Comunicação Pública: estado, mercado, sociedade e interesse público. 2. ed. São Paulo: Atlas, 2009. p. 1-33.

COSTA, Sérgio. Movimentos sociais, democratização e a construção de esferas públicas locais. Revista brasileira de ciências sociais, São Paulo, v. 12, n. 35, out. 1997.

ESTEVES, João José Pissarra Nunes. Espaço público e democracia: comunicação, processos de sentido e identidade social. São Leopoldo: Unisinos, 2003.

GOMES, Wilson; MAIA, Rousiley C. M. Comunicação e democracia: problemas e perspectivas. São Paulo: Paulus, 2008. 372 p.

LIVINGSTONE, Sonia. On the relation between audiences and publics: why aundience and public? London: LSE Research Online, 2005. Disponível em: <http://eprints.lse.ac.uk/437/1/chap_1_livingstone_final.pdf>. Acesso em: 10 abr. 2012.

MARTIN-BARBERO, Jesus. Dos meios às mediações: comunicação, cultura e hegemonia. Rio de Janeiro: Ed. UFRJ, 2003

TELLES, Vera da Silva. Sociedade civil e a construção de espaços públicos. In: DAGNINO, Evelina (Org.). Anos 90: política e sociedade no Brasil. São Paulo: Brasiliense, 1994.

THOMPSON, John B. Ideologia e cultura moderna: teoria social crítica na era dos meios de comunicação de massa. Petrópolis: Vozes, 1995.

TORO, Jose Bernardo; WERNECK, Nisia Maria Duarte. Mobilização social: um modo de construir a democracia e a participação. Belo Horizonte: Autêntica, 2007. 